\title{
LETTER
}

\section{The AKI care bundle: all bundle components are created equal-are they?}

\author{
Thilo C. von Groote ${ }^{1}$, Marlies Ostermann², Lui G. Forni ${ }^{3,4}$, Melanie Meersch-Dini ${ }^{1}$ and Alexander Zarbock ${ }^{1 *}$ (D) on \\ behalf of the PrevAKI Investigators
}

() 2021 Crown

\section{Dear Editor,}

Acute kidney injury (AKI) remains a common and significant complication in critically ill patients. As no curative treatment exists, prevention of AKI is paramount, especially in high-risk patients. Several randomized controlled trials suggest that a biomarker-guided implementation of the Kidney Disease Improving Global Outcomes (KDIGO) care bundle reduces the incidence of AKI postoperatively [1-3]. Implementation of this care bundle is recommended in high-risk patients after cardiac surgery [4]. This comprises regular monitoring of kidney function, hemodynamic optimization, and consideration of advanced hemodynamic monitoring, as well as avoidance of hyperglycemia, nephrotoxic drugs, and radiocontrast agents, if possible.

So far, the impact of each individual component of the bundle is unclear. Better understanding would enable prioritization, resource-allocation and clinical management of those at high risk of AKI. To investigate the treatment effects of individual bundle components, we combined data of the two PrevAKI-trials including 554 cardiac surgery patients at high risk for AKI, as defined by elevated urinary biomarkers TIMP2*IGFBP7 [1, 2]. Patients were randomized to standard care versus implementation of the care bundle (Supplementary S1).

Univariate logistic regression of the bundle's components was performed as a risk factor analysis of the whole cohort. Following this, individual treatment effects were analyzed, using the same method for the intervention group only (Fig. 1a). Hypotension, low cardiac

*Correspondence: zarbock@uni-muenster.de

${ }^{1}$ Department of Anaesthesiology, Intensive Care and Pain Medicine, University Hospital Münster, Münster, Germany

Full author information is available at the end of the article index (CI), and use of radiocontrast agents significantly increased the risk for AKI. Optimizing the hemodynamic situation (avoiding hypotension and a low cardiac output state) and avoidance of nephrotoxic drugs were the most important measures to prevent AKI (Fig. 1a). Based on these results, we investigated the role of hemodynamic optimization. AKI occurred significantly less frequently, when hypotension and low CI were prevented (Fig. 1b), particularly for severe stages of AKI.

Testing the effect of hemodynamic optimization, further analyses demonstrated the effect of hemodynamic optimization between the first and the consecutive hemodynamic measurement (Fig. 1c). Patients with hypotension at presentation had statistically lower rates of AKI when successfully optimized until the next measurement, compared to patients in which median arterial pressure optimization could not be achieved. AKI rates were lowest in patients in which hypotension was avoided entirely. Differences of AKI rates in patients with successful optimization of cardiac index were not statistically significant.

In conclusion, our findings demonstrate the importance of maintaining adequate systemic blood pressure and cardiac output. If hypotension or low cardiac output occurs, timely hemodynamic optimization should be performed to prevent AKI. Whilst our analyses suggested a possible role for radiocontrast agents and nephrotoxic drugs, these factors had wide confidence intervals, indicating low certainty of these findings. Besides hemodynamic optimization, other bundle components had little or no impact on the bundle's overall effectiveness.

For patients at risk for AKI, we recommend avoiding even short periods of hypotension [5]. Finally, we suggest that improvement of cardiac index using inotropes,

\section{Springer}


a

\begin{tabular}{|c|c|c|c|c|}
\hline Analysis: & \multicolumn{2}{|c|}{$\begin{array}{r}\text { Risk factor (intervention + control } \\
\text { arms; } \mathrm{n}=554)\end{array}$} & \multicolumn{2}{c|}{$\begin{array}{c}\text { Individual treatment effect } \\
\text { (intervention arm; n=274) }\end{array}$} \\
\hline OR (95\%CI) & p-value & OR (95\%CI) & p-value \\
\hline Hypotension & $2.30(1.61-3.27)$ & $<0.05$ & $2.37(1.41-3.98)$ & $<0.05$ \\
\hline cardiac index < 3.0 & $1.93(1.10-3.38)$ & $<0.05$ & $1.97(1.11-3.52)$ & $<0.05$ \\
\hline $\begin{array}{c}\text { cardiac index < 3.0 } \\
\text { and/or hypotension }\end{array}$ & $2.25(1.15-4.39)$ & $<0.05$ & $2.10(1.06-4.17)$ & $<0.05$ \\
\hline hyperglycemia & $1.44(0.99-2.10)$ & 0.056 & $1.07(0.64-1.77)$ & 0.8 \\
\hline Use of ACEi or ARBs & $1.19(0.75-1.90)$ & 0.456 & $0.85(0.41-1.76)$ & 0.85 \\
\hline Use of contrast & $3.57(1.55-8.24)$ & $<0.05$ & $2.57(0.81-8.18)$ & 0.11 \\
\hline agents & & & & $<0.05$ \\
\hline nephrotoxic drugs & $1.58(0.91-2.73)$ & 0.107 & $8.19(1.86-36.02)$ & $<$ \\
\hline
\end{tabular}

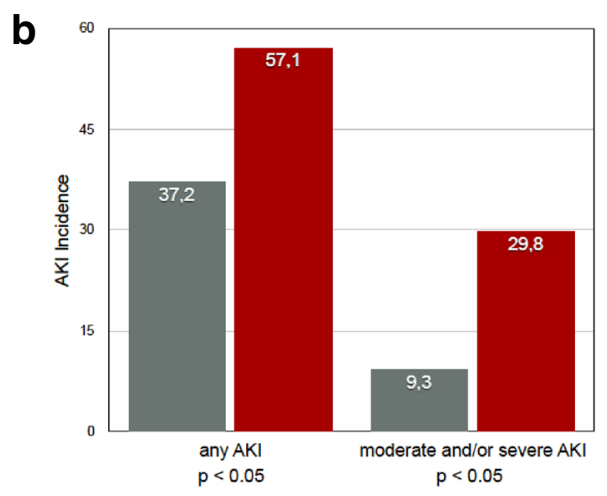

AKI rate in $\%$

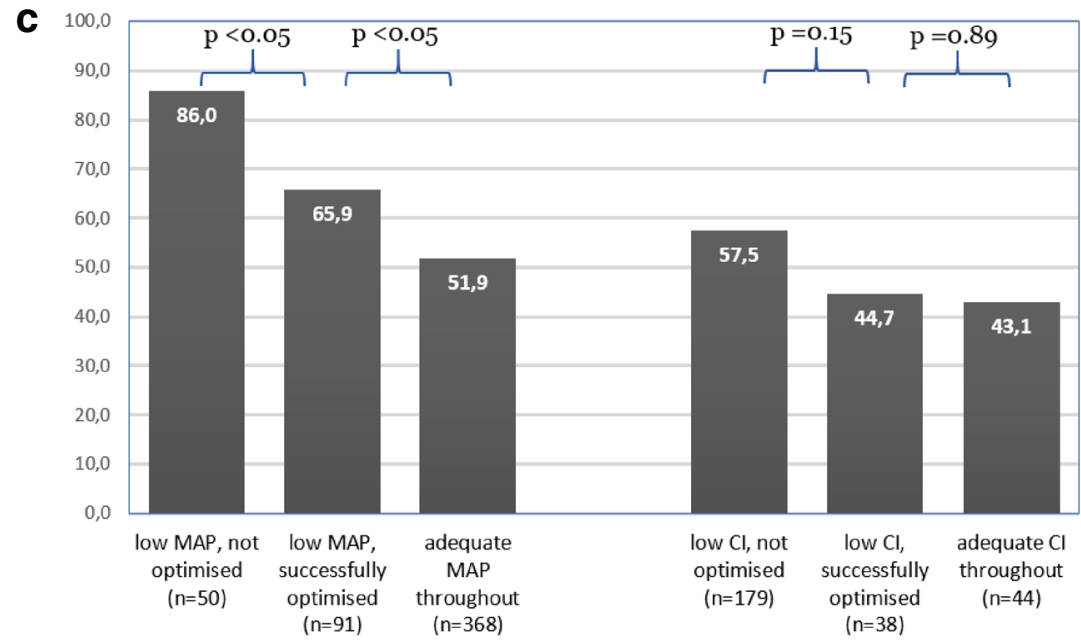

Fig. 1 a Univariate, binary logistic regression analysis for development of any AKI. ACEi angiotensin-converting enzyme inhibitors, ARBs angiotensin receptor blockers, OR odds ratio, MAP median arterial pressure, Cl cardiac index. Hypotension: MAP $<60 \mathrm{mmHg}$ on one reading or MAP $<65 \mathrm{mmHg}$ on two readings during the intervention period. Hyperglycemia defined as: blood glucose levels $\geq 150 \mathrm{mg} / \mathrm{dl}$ longer than three hours during intervention period. $\mathbf{b}$ Hemodynamic status and AKI incidence. (gray= high MAP and/or Cl; red=low MAP and/or Cl). c Treatment effects of hemodynamic optimization for AKI prevention 
may be a key, yet all too often ignored, aspect of AKI prevention.

\section{Supplementary Information}

The online version contains supplementary material available at https://doi. org/10.1007/s00134-021-06601-0.

\section{Author details}

${ }^{1}$ Department of Anaesthesiology, Intensive Care and Pain Medicine, University Hospital Münster, Münster, Germany. ${ }^{2}$ Department of Critical Care and Nephrology, King's College London, Guy's and St Thomas'Hospital, London SE1 7EH, UK. ${ }^{3}$ Department of Clinical and Experimental Medicine, Faculty of Health Sciences, University of Surrey, Guildford, UK. ${ }^{4}$ Department of Intensive Care Medicine, Royal Surrey County Hospital, Egerton Road, Guildford GU2 7XX, Surrey, UK.

\section{Acknowledgements}

We would like to thank Mr Jannik Feld, MSc, Institute of Biostatistics and Clinical Research, University of Münster, Münster, Germany and Dr. rer. nat. Joachim Gerß, Institute of Biostatistics and Clinical Research, University of Münster, Münster, Germany, for their statistical advice. Furthermore, we thank all PrevAKI-investigators for their contribution, namely Christoph Schmidt, Department of Anaesthesiology, Intensive Care and Pain Medicine, University Hospital Münster, Münster, Germany. Andreas Hoffmeier, Department of Cardiac Surgery, University of Münster, Münster, Germany. Hugo van Aken, Department of Anaesthesiology, Intensive Care and Pain Medicine, University Hospital Münster, Münster, Germany. Carola Wempe, Department of Anaesthesiology, Intensive Care and Pain Medicine, University Hospital Münster, Münster, Germany. Mira Küllmar, Department of Anaesthesiology, Intensive Care and Pain Medicine, University Hospital Münster, Münster, Germany. Gianluca Lucchese, Department of Critical Care \& Nephrology, King's College London, Guy's \& St Thomas' Hospital, London, SE1 7EH, UK. Kamran Baig, Department of Critical Care \& Nephrology, King's College London, Guy's \& St Thomas' Hospital, London, SE1 7EH, UK. Armando Cennamo, Department of Critical Care \& Nephrology, King's College London, Guy's \& St Thomas' Hospital, London, SE1 7EH, UK. Ronak Rajani, Department of Critical Care \& Nephrology, King's College London, Guy's \& St Thomas' Hospital, London, SE1 7EH, UK. Stuart McCorkell, Department of Critical Care \& Nephrology, King's College London, Guy's \& St Thomas' Hospital, London, SE1 7EH, UK. Christian Arndt, Department of Anaesthesiology and Intensive Care Medicine, University Hospital Marburg, Marburg, Germany. Hinnerk Wulf, Department of Anaesthesiology and Intensive Care Medicine, University Hospital Marburg, Marburg, Germany. Marc Irqsusi, Department of Cardiovascular Surgery, Philipps University of Marburg, Marburg, Germany. Fabrizio Monaco, Department of Anesthesia and Intensive Care, Istituto di Ricovero e Cura a Carattere Scientifico San Raffaele Scientific Institute, Milan, Italy. Ambra Licia Di Prima, Department of Anesthesia and Intensive Care, Istituto di Ricovero e Cura a Carattere Scientifico San Raffaele Scientific Institute, Milan, Italy. Mercedes García Alvarez, Department of Anesthesiology, Hospital de la Santa Creu i Sant Pau, Barcelona, Spain. Stefano Italiano, Department of Anesthesiology, Hospital de la Santa Creu i Sant Pau, Barcelona, Spain. Jordi Miralles Bagan, Department of Anesthesiology, Hospital de la Santa Creu i Sant Pau, Barcelona, Spain. Gudrun Kunst, Department of Anesthetics, King's College Hospital, Denmark Hill, London, United Kingdom. Shrijit Nair, Department of Anesthetics, King's College Hospital, Denmark Hill, London, United Kingdom. Camilla L'Acqua, Department of Anesthesia and Critical Care, Centro Cardiologico Monzino Istituto di Ricovero e Cura a Carattere Scientifico, Milan, Italy. Eric Hoste, Department of Intensive Care Medicine, University Hospital Gent, Gent, Belgium. Wim Vandenberghe, Department of Intensive Care Medicine, University Hospital Gent, Gent, Belgium. Patrick M. Honore, Department of Intensive Care, CHU Brugmann University Hospital, Brussels, Belgium. John A. Kellum, Center for Critical Care Nephrology, Department of Critical Care Medicine, University of Pittsburgh, Pittsburgh, Pennsylvania. Philippe Grieshaber, Department of Cardiac Surgery, University Hospital Giessen, Giessen, Germany. Christina Massoth, Department of Anaesthesiology, Intensive Care and Pain Medicine, University Hospital Münster, Münster, Germany. Raphael Weiss, Department of Anaesthesiology, Intensive Care and Pain Medicine, University Hospital Münster, Münster, Germany.

\section{Author contributions}

TCVG, MMD and AZ conceived and designed the study and drafted the manuscript. TVCG performed the data retrieval. TVCG, MMD and AZ performed the statistical analysis. TVCG, MMD, MO, LGF and AZ were involved in the interpretation of the data, and made critical revisions to the manuscript. All authors read and approved the final version of the manuscript to be published.

\section{Funding}

Open Access funding enabled and organized by Projekt DEAL. The trials were supported by the German Research Foundation (KFO342-1, ZA428/18-1 and ZA428/21-1) to Professor Alexander Zarbock.

\section{Declarations}

\section{Conflict of interest}

TCVG and $\mathrm{MO}$ declared no conflict of interest. AZ reported receiving research grants from Baxter, Fresenius, Astute Medical, and Astellas and receiving personal fees from Fresenius, AM Pharma and Biomerieux. MM reported receiving personal fees from Astute Medical, FMC, and Baxter. LGF declared research support and personal fees from Astute Medical, La Jolla Pharmaceuticals, Medibeacon, Baxter, and Fresenius.

\section{Ethical approval}

Not required.

\section{Open Access}

This article is licensed under a Creative Commons Attribution-NonCommercial 4.0 International License, which permits any non-commercial use, sharing, adaptation, distribution and reproduction in any medium or format, as long as you give appropriate credit to the original author(s) and the source, provide a link to the Creative Commons licence, and indicate if changes were made. The images or other third party material in this article are included in the article's Creative Commons licence, unless indicated otherwise in a credit line to the material. If material is not included in the article's Creative Commons licence and your intended use is not permitted by statutory regulation or exceeds the permitted use, you will need to obtain permission directly from the copyright holder. To view a copy of this licence, visit http://creativecommons.org/licen ses/by-nc/4.0/.

\section{Publisher's Note}

Springer Nature remains neutral with regard to jurisdictional claims in published maps and institutional affiliations.

Accepted: 3 December 2021

Published online: 18 December 2021

\section{References}

1. Meersch M, Schmidt C, Hoffmeier A, Van Aken H, Wempe C, Gerss J, Zarbock A (2017) Prevention of cardiac surgery-associated AKI by implementing the KDIGO guidelines in high risk patients identified by biomarkers: the PrevAKI randomized controlled trial. Intensive Care Med 43(11):1551-1561. https://doi.org/10.1007/s00134-016-4670-3

2. Zarbock A, Küllmar M, Ostermann M, Lucchese G, Baig K, Cennamo A Rajani R, McCorkell S, Arndt C, Wulf H, Irqsusi M, Monaco F, Di Prima AL, García Alvarez M, Italiano S, Miralles Bagan J, Kunst G, Nair S, L'Acqua C, Hoste E et al (2021) Prevention of cardiac surgery-associated acute kidney injury by implementing the KDIGO guidelines in high-risk patients identified by biomarkers: the PrevAKI-multicenter randomized controlled trial. Anesth Analg 133(2):292-302. https://doi.org/10.1213/ANE.0000000000 005458

3. Göcze I, Jauch D, Götz M, Kennedy P, Jung B, Zeman F, Gnewuch C, Graf BM, Gnann W, Banas B, Bein T, Schlitt HJ, Bergler T (2018) Biomarkerguided intervention to prevent acute kidney injury after major surgery: the prospective randomized BigpAK study. Ann Surg 267(6):1013-1020. https://doi.org/10.1097/SLA.0000000000002485 
4. Joannidis M, Drum I W, Forni LG, Groeneveld A, Honore PM, Hoste E, Ostermann M, Oudemans-van Straaten HM, Schetz M (2017) Prevention of acute kidney injury and protection of renal function in the intensive care unit: update 2017: expert opinion of the Working Group on Prevention, AKI section, European Society of Intensive Care Medicine. Intensive Care Med 43(6):730-749. https://doi.org/10.1007/s00134-017-4832-y
5. Pickkers $P$, Ostermann M, Joannidis M, Zarbock A, Hoste E, Bellomo R, Prowle J, Darmon M, Bonventre JV, Forni L, Bagshaw SM, Schetz M (2017) The intensive care medicine agenda on acute kidney injury. Intensive Care Med 43(9):1 198-1209. https://doi.org/10.1007/s00134-017-4687-2 